\title{
Future perspectives in genetics of kidney disease: resistance genes
}

\section{Editorial}

Patients with a systemic disorder such as primary hypertension, or diabetes can develop progressive kidney disease. The involvement of the kidney in these systemic disorders results in various forms of glomerulosclerosis and tubulo-interstitial fibrosis as common pathological features. This is accompanied by loss of renal function and increased cardiovascular mortality. However, the predisposition to develop kidney disease does not occur in all patients with a systemic disease. Epidemiological and genetic studies show that the predisposition to develop kidney disease in patients with a systemic disorder is genetically inherited. For most genetic studies whole genome association studies, gene expression profiles, and next generation sequencing have resulted in either identification of responsible genes, or mapping of the quantitative trait loci of candidate modifying genes. Since gene-association studies may contain false-positive reports, additional confirmation is usually required by a genetic meta-analysis to extract the correct genetic information. ${ }^{1-3}$ Genetic association studies for susceptibility for focal segmental glomerulosclerosis [FSGS] show that this develops in 50\% of patients with primary hypertension. ${ }^{4}$ Meta-analysis of patients with diabetes show that at least 25 genes candidate genes are involved in the development of diabetic nephropathy that develops in $30-40 \%$ of these patients. ${ }^{3}$

Animal studies in MWF rats with primary hypertension show that susceptibility to develop FSGS is determined by back ground genes from the rodent strain. ${ }^{5}$ Consomic rat strains from susceptible strains with resistant strains show that primary hypertension resulting in FSGS are confined to QTLs on chromosome 6 and 8 from susceptible strains. ${ }^{6,7}$ A recently reported novel explanation is the existence of genes that prevent development of progressive renal disease and protect the kidney for involvement in the systemic disease. Interesting information is provided by the ICGN mouse. ${ }^{8}$ This tensin- 2 deficient mouse strain develops progressive glomerulosclerosis and end stage renal disease. However when this genetic deficiency is transferred to mice from BL6, or 129 strains, the kidney disease does either not develops, or has a very mild course of disease. ${ }^{9}$ By generating Consomic strains of chromosomes from resistant strains tot susceptible mice Sasaki and his colleagues show the existence of quantitative trait loci that confer resistance to renal disease.$^{10}$ If this finding applies to other systemic disorders like primary hypertension and diabetes, the therapeutic potential will be substantial. Identification of resistanceassociated genes and their function will open possibilities to prevent or restore progressive kidney disease in large numbers of patients.

\section{Acknowledgements}

None.
Volume I Issue 3 - 2015

\author{
Emile de Heer \\ Department of Pathology, Leiden University Medical Center,The \\ Netherlands
}

Correspondence: Emile de Heer, Department of Pathology, Leiden University Medical Center, Leiden, The Netherlands, Email E.de_Heer@lumc.nl

Received: October 27, 2015 | Published: October 30, 2015

\section{Conflict of interest}

The author declares no conflict of interest.

\section{References}

1. Rahmattulla C, Mooyaart AL, van Hooven D, et al. Genetic variants in ANCA-associated vasculitis: a meta-analysis. Ann Rheum Dis. 2015;75(9):1687-1692.

2. Buurma AJ, Turner RJ, Driessen JH, et al. Genetic variants in preeclampsia: a meta-analysis. Hum Reprod Update. 2013;19(3):289-303.

3. Mooyaart AL, Valk EJ, van Es LA, et al. Genetic associations in diabetic nephropathy: a meta-analysis. Diabetologia. 2011;54(3):544-553.

4. Padmanabhan S, Caulfield M, Dominiczak AF. Genetic and molecular aspects of hypertension. Circ Res. 2015;116:937-959.

5. Pravenec M, Kren V, Landa V, et al. Recent progress in the genetics of spontaneously hypertensive rats. Physiol Res. 2014;63(Suppl 1):1-8.

6. Schulz A, Kreutz R. Mapping genetic determinants of kidney damage in rat models. Hypertens Res. 2012;35(7):675-694.

7. Van Es N, Schulz A, Ijpelaar D, et al. Elimination of severe albuminuria in aging hypertensive rats by exchange of 2 chromosomes in doubleconsomic rats. Hypertension. 2011;58(2):219-224.

8. Cho AR, Uchio YK, Torigai T, et al. Deficiency of the tensin2 gene in the ICGN mouse: an animal model for congenital nephrotic syndrome. Mamm Genome. 2006;17(5):407-416.

9. Nishino T, Sasaki N, Nagasaki K, et al. The 129 genetic background affects susceptibility to glomerulosclerosis in tensin2-deficient mice. Biomed Res. 2012;33(1):53-56.

10. Sasaki H, Sasaki N, Nishino T, et al. Quantitative trait Loci for resistance to the congenital nephropathy in tensin 2-deficient mice. PLoS One. 2014;9(6):e99602. 